\title{
Hyperendemicity, heterogeneity and spatial overlap of leprosy and cutaneous leishmaniasis in the southern Amazon region of Brazil
}

\author{
Amanda Gabriela de Carvalho, ${ }^{1,2}$ João Gabriel Guimarães Luz, ${ }^{1,3}$ João Victor Leite Dias, ${ }^{4}$ \\ Anuj Tiwari, ${ }^{3}$ Peter Steinmann, ${ }^{5,6}$ Eliane Ignotti ${ }^{2,7}$ \\ ${ }^{1}$ School of Medicine, Institute of Exact and Natural Sciences, Federal University of Rondonópolis, \\ Rondonópolis, Brazil; ${ }^{2}$ School of Medicine, Post-Graduation Program in Health Sciences, Federal \\ University of Mato Grosso, Cuiabá, Mato Grosso, Brazil; ${ }^{3}$ Department of Public Health, Erasmus \\ University Medical Center, Rotterdam, The Netherlands; ${ }^{4}$ School of Medicine, Federal University of \\ Jequitinhonha and Mucuri Valleys, Teófilo Otoni, Minas Gerais, Brazil; ${ }^{5}$ Swiss Tropical and Public Health \\ Institute, Basel, Switzerland; ${ }^{6}$ University of Basel, Switzerland; ${ }^{7}$ School of Health Sciences, Post- \\ Graduation Program Environment Sciences, State University of Mato Grosso, Cáceres, Mato Grosso, Brazil
}

\begin{abstract}
Neglected tropical diseases characterized by skin lesions are highly endemic in the state of Mato Grosso, Brazil. We analyzed
\end{abstract}

\footnotetext{
Correspondence: Amanda Gabriela de Carvalho, School of Medicine, Institute of Exact and Natural Sciences, Federal University of Rondonópolis, 5055 Estudantes Avenue, Rondonópolis, 78736-900, Mato Grosso, Brazil.

Tel.: +55.66 .34104004 .

E-mail: amandagcarvalho@hotmail.com
}

Key words: Leprosy; cutaneous leishmaniasis; neglected tropical diseases; epidemiology; spatial analysis; Brazil.

Acknowledgments: The authors are grateful to the Epidemiological Surveillance Sector of the Health Department of the State of Mato Grosso for direct access to the databases.

Funding: This study was supported by the Brazilian National Council for Scientific and Technological Development $(\mathrm{CNPq})$, process number 421138/2018-1. This study was also financed in part by the Coordenação de Aperfeiçoamento de Pessoal de Nível Superior - Brasil (CAPES) - Finance Code 001.

Conflict of interests: The authors declare no potential conflict of interests.

Ethical approval: This study was approved by the Research Ethics Committee of the Federal University of Mato Grosso, Campus Rondonópolis, CAAE number: 01735018.6.0000.8088.

Received for publication: 26 April 2020

Accepted for publication: 13 July 2020.

(C) Copyright: the Author(s), 2020

Licensee PAGEPress, Italy

Geospatial Health 2020; 15:892

doi:10.4081/gh.2020.892

This article is distributed under the terms of the Creative Commons Attribution Noncommercial License (CC BY-NC 4.0) which permits any noncommercial use, distribution, and reproduction in any medium, provided the original author(s) and source are credited. the spatial distribution of leprosy and Cutaneous Leishmaniasis (CL) and identified the degree of overlap in their distribution. All new cases of leprosy and CL reported between 2008 and 2017 through the national reporting system were included in the study. Scan statistics together with univariate Global and Local Moran's $I$ were employed to identify clusters and spatial autocorrelation for each disease, with the spatial correlation between leprosy and CL measured by bivariate Global and Local Moran's I. Finally, we evaluated the demographic characteristics of the patients. The number of leprosy $(\mathrm{N}=28,204)$ and $\mathrm{CL}(\mathrm{N}=24,771)$ cases in Mato Grosso and the highly smoothed detection coefficients indicated hyperendemicity and spatial distribution heterogeneity. Scan statistics demonstrated overlap of high-risk clusters for leprosy $(\mathrm{RR}=2.0 ; \mathrm{P}<0.001)$ and $\mathrm{CL}(\mathrm{RR}=4.0 ; \mathrm{P}<0.001)$ in the North and Northeast mesoregions. Global Moran's I revealed a spatial autocorrelation for leprosy $(0.228 ; \mathrm{P}=0.001)$ and $\mathrm{CL}(0.311 ; \mathrm{P}=$ $0.001)$ and a correlation between them $(0.164 ; \mathrm{P}=0.001)$. Both diseases were found to be concentrated in urban areas among men aged 31-60 years, of brown-skinned ethnicity and with a low educational level. Our findings indicate a need for developing integrated and spatially as well as socio-demographically targeted public health policies.

\section{Introduction}

Neglected Tropical Diseases (NTDs) are a diverse group of currently 20 treatable and preventable conditions that affect more than 1 billion people, mainly in low-income countries in the tropics and subtropics (Mitjà et al., 2017; WHO, 2017). To efficiently treat NTDs, there is a need to improve the quality and effectiveness of health services. Shared epidemiological, demographic, and geographic parameters call for integration of NTDs control programmes (Standley et al., 2018). A distinct group of NTDs presents with skin manifestations, including leprosy and Cutaneous Leishmaniasis (CL). Although causing limited mortality, they present a chronic disease course that may result in significant morbidity due to physical disabilities and social stigma (Engelman et al., 2016; WHO, 2017).

Leprosy is mainly caused by the intracellular bacterium Mycobacterium leprae, with the infection predominantly transmitted through prolonged contact between susceptible individuals 
and untreated patients, most likely through the inhalation of respiratory droplets. The broad clinical spectrum of leprosy is related to the immune response developed by the host, which can result in different types of skin lesions, nerve damage and deformities (Rodrigues and Lockwood, 2011). Annually, more than 200,000 new leprosy cases are reported worldwide, with $80 \%$ of new cases concentrated in three countries, i.e. India, Brazil and Indonesia. Brazil reports approximately $90 \%$ of all leprosy patients in Latin America (WHO, 2017). In 2018, a total of 28,660 new leprosy cases were observed nationwide, translating into an incidence of 13.7 cases per 100,000 inhabitants (WHO, 2019).

$\mathrm{CL}$ is caused by protozoa of the genus Leishmania, which are transmitted by the bite of female sand flies (Diptera: Psychodidae). The disease affects the skin and mucous membranes and has a wide range of clinical manifestations. Variations are due to the infecting Leishmania species and, similarly to leprosy, the pattern of the immune response developed by the patient. According to the Ministry of Health $(\mathrm{MoH})$ of Brazil between 0.7 and 1.3 million new leishmaniasis cases are reported every year from approximately 85 countries $(\mathrm{MoH}, 2017)$. Brazil is among the ten countries that together report $70-75 \%$ of the global CL incidence. Between 1995 to 2014, the country reported an average of 25,763 new CL cases per year (Alvar et al., 2012; MoH, 2017).

For both leprosy and CL, the surveillance and control strategies currently recommended in Brazil are based on early diagnosis and treatment of cases, epidemiological surveillance and health education. In addition, for leprosy, strategies also include the prevention and treatment of physical disabilities, as well as contact examination. For CL, vector monitoring and control should be conducted (MoH, 2016; 2017).

Leprosy and CL share many epidemiological features that commonly overlap geographically (Martínez et al., 2018). Geographical Information Systems (GIS) has been widely employed to identify spatial patterns and priority areas for leprosy (Silva et al., 2017) and CL, but their co-endemicity has seldom been evaluated (Melo et al., 2017). Indeed, studies addressing the joint spatial patterns of leprosy and CL are scarce despite the relevance for the development of targeted and integrated control and surveillance programs (Engelman et al., 2016). The aim of this study was to assess the joint spatial distribution of leprosy and CL in the state of Mato Grosso, Brazil where both diseases are highly endemic. To that end, an epidemiological and ecological study in that area was conducted over the period 2008-2017.

\section{Materials and methods}

\section{Study area}

The state of Mato Grosso is located in central-western Brazil in the southern Amazon region (Figure 1A). It occupies an area of 903,202.5 $\mathrm{km}^{2}$ and presents the three main continental biomes of the country: Amazônia (rainforest), Pantanal (wetland) and Cerrado (savanna). According to the Institute of Geography and Statistics of Brazil (IBGE) the population, distributed across 141 municipalities and five mesoregions (Figure 1B), was estimated at 3,484,466 individuals in 2019 (IBGE, 2019). According to the latest $\mathrm{MoH}$ Epidemiological Bulletin, Mato Grosso reported the highest average detection rates of leprosy (92.6 cases/ 100,000 inhabitants) of all states between 2009 and 2018 (MoH, 2020). In addition, it currently ranks third among the Brazilian states with respect to the number of reported CL cases, with an annual average of 2,510 cases between 2009 and 2018 (DATASUS, 2020).

\section{Data sources and study variables}

In Brazil, leprosy and CL cases are diagnosed through both passive surveillance and active case detection. As notifiable diseases, data on epidemiological, clinical, and laboratory features of all confirmed cases should immediately be recorded in a specific form of the Brazilian Notifiable Diseases Information System (Sistema de Informação de Agravos de Notificação, SINAN). The reporting trig-

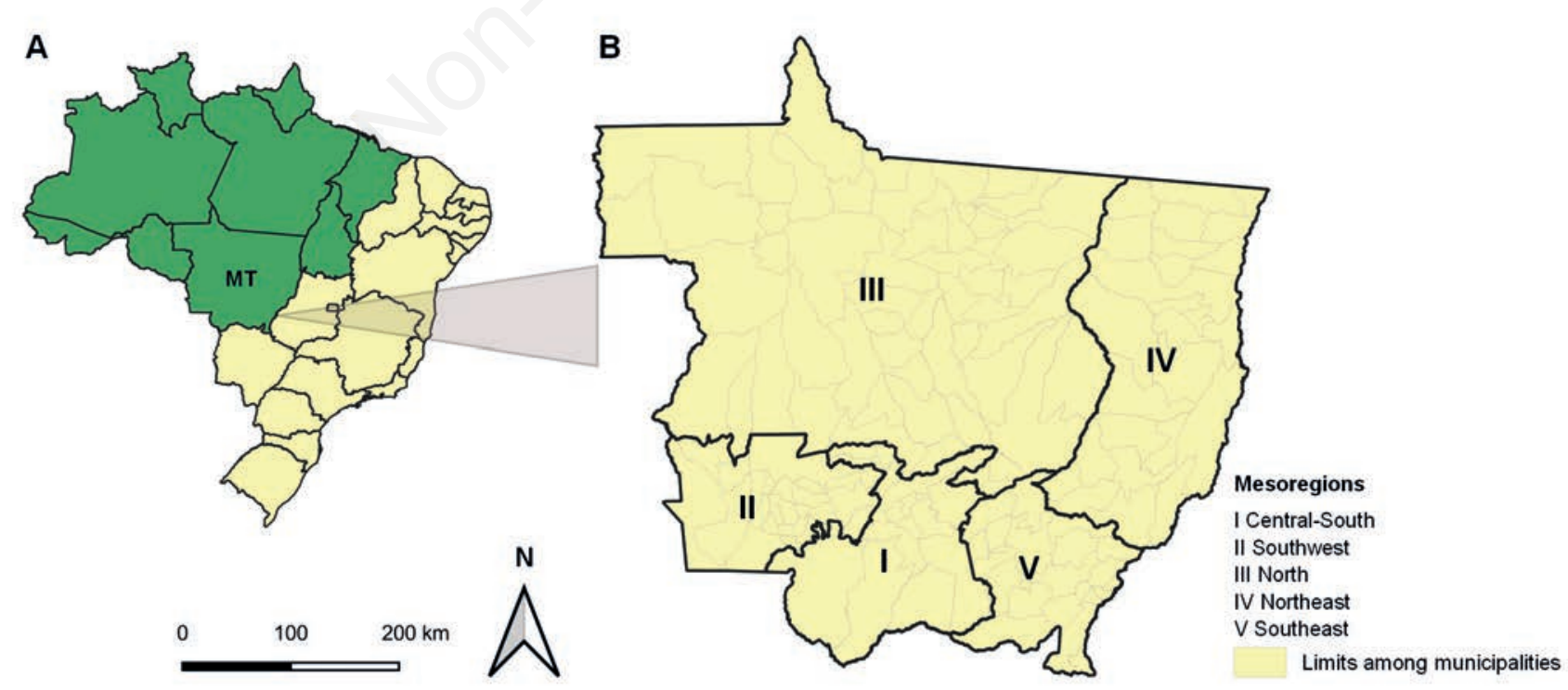

Figure 1. Geographic characterization of the study area. (A) Location of the state of Mato Grosso (MT) in the Brazilian Amazon region green area; (B) Division of the state into five mesoregions with gray lines corresponding to the municipality borders. 
gers investigation and follow-up by local surveillance department until the clinical outcome has been established.

The primary data source was the SINAN. Specifically, we analyzed the leprosy and CL sub-databases provided by the Epidemiological Surveillance Sector of the Health Department of the state of Mato Grosso. The records of the sociodemographic variables related to the leprosy and CL patients are kept in a database that includes sex, age group, ethnic group/colour, schooling, area of residence, and municipality of residence. All new cases due to both diseases reported between 2008 and 2017 were included in the analysis after excluding duplicates, non-autochthonous records (patients diagnosed in Mato Grosso but resident elsewhere), error or change in diagnosis, and relapses. Annual estimates of the total population for all municipalities and the municipal cartographic shape files were obtained from the IBGE (IBGE, 2020).

\section{Data analysis}

Data management and analysis were performed using Microsoft ${ }^{\text {TM }}$ Office Excel 2010 (Microsoft Corp., Santa Rosa, CA, USA) and STATA/SE 12.0 (Stata Corp LP, College Station, TX, USA). The crude annual infection detection coefficient per 100,000 inhabitants was calculated by dividing the number of cases diagnosed in a particular year by the estimated population of the state that year. Next, the absolute and relative frequencies of the sociodemographic variables were calculated for each disease with $95 \%$ confidence interval using the Wald method. In addition, a Chi-square $\left(\chi^{2}\right)$ test was applied to compare the proportions. Differences with $p<0.05$ were considered statistically significant.

For spatial analysis, the data were aggregated according to the municipality of the patients. First, the detection coefficient for leprosy and CL for each municipality was smoothed using the Global Empirical Bayesian Estimator (GEBE), in GeoDa 1.10 software (University of Chicago, Chicago, IL, USA). The GEBE decreases the effect of random fluctuations and data instability by smoothing the crude rate towards an overall mean (Assunção et al., 1998). Smoothed detection coefficients were presented as quartiles in thematic maps.

Kulldorff's spatial scan statistics (Kulldorff and Nagarwalla, 1995) were used to identify potential spatial clusters of both diseases. A purely spatial analysis was conducted based on a discrete
Poisson distribution of probabilities and employing the following parameters: number of cases of each disease, average population size of the municipalities and geographic coordinates of their centroids (Lambert Conformal Conic Projection, metric units). Spatial clusters were detected considering a maximum radius of the circular geographic window that aggregates until $50 \%$ of the population at risk, as advised by Kulldorff and Nagarwalla (1995). For each cluster, a likelihood ratio test was applied to test the null hypothesis of spatial randomness versus the alternative hypothesis that the risks within and outside the circular window were different. A 5\% level of cluster significance was obtained through 999 Monte Carlo simulations. Only significant clusters with high risk for disease occurrence were considered. The analysis was conducted with the SaTScan ${ }^{\mathrm{TM}} 9.3$ software (National Cancer Institute, Bethesda, MD, USA).

Global Moran's I was calculated to investigate the overall presence of patterns or spatial autocorrelation in the smoothed detection coefficients over the unit of analysis for each disease. In summary, spatial autocorrelation measures the influence that the values in neighbouring municipalities have on the observed value of each municipality (Aturinde et al., 2019). The Moran's I ranges from 1 to +1 ; values close to zero suggest spatial randomness while values close to +1 or -1 indicate positive (cluster) and negative (scatter) spatial autocorrelation, respectively. In addition, the Local Moran's I or Local Indicator of Spatial Association (LISA) was employed to identify the local spatial clusters. The analysis took into account the smoothed detection coefficient of each municipality to verify the presence of similarities with neighbouring municipalities. A queen contiguity-based spatial weights matrix was employed to define neighbours. Areas were classified as HighHigh (municipalities with positive spatial autocorrelation and positive values among the neighbours) and Low-Low (municipalities with negative spatial autocorrelation and negative values among the neighbours; Carvalho et al., 2004).

Finally, the Bivariate global and Local Moran's I (also known as BiLISA) was calculated as a measure of spatial correlation between the occurrence of leprosy in one municipality and CL in the neighbouring municipalities (Aturinde et al., 2019). All Moran's $I$ analyses were performed with the GeoDa 1.10 software. The statistical significance of the $I$ 's were checked in a pseudo sig-

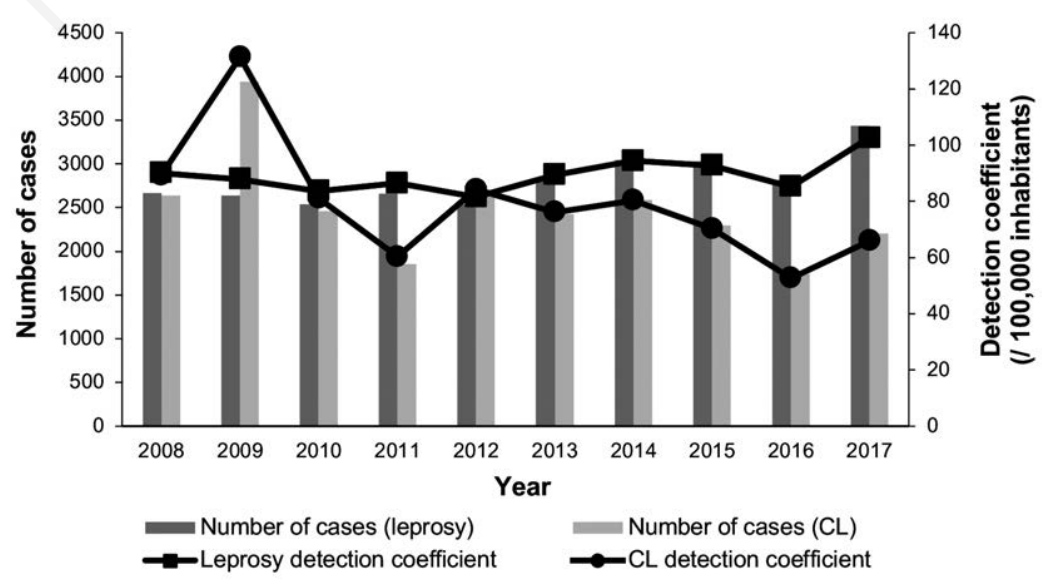

Figure 2. Annual absolute number of reported cases and crude detection coefficient of leprosy and Cutaneous Leishmaniasis (CL) in the state of Mato Grosso, Brazil 2008-2017. 
nificance test based on 999 random permutations of the values among the evaluated areas. The spatial autocorrelation and correlation was considered significant at $\mathrm{P}<0.05$. All products of the spatial analyzes were transformed into thematic maps in QGIS 3.4.0 software (QGIS, 2018).

\section{Results}

From 2008 to 2017, 28,204 leprosy cases and 24,771 CL cases were reported in the state of Mato Grosso, with an annual average of 2,820 and a Standard Deviation (SD) of 281.3 and 2,477 (SD: $601.0)$, respectively. The crude detection coefficient of leprosy followed no obvious trend over the years, with an average of 89.4 (SD: 6.1) cases/100,000 inhabitants and a recent peak in 2017 (102.6 cases/100,000 inhabitants). In contrast, CL presented an average detection coefficient of 79.1 (SD: 21.5) cases/100,000 inhabitants, with a peak in 2009 (131.3 cases/100,000 inhabitants) followed by a strong decrease in 2010 and 2011 (60.2 cases/100,000 inhabitants). After that, the detection coefficients of
CL were generally even or followed a slightly decreasing trend (Figure 2).

Autochthonous cases of leprosy and CL were reported from all municipalities of Mato Grosso. The absolute numbers ranged from 3 to 2,726 for leprosy, and from 1 to 1,262 for CL. Cuiabá, Juína, Rondonópolis, Sinop and Tangará da Serra were municipalities with the highest absolute numbers of cases for both diseases. While Cuiabá reported the highest number of leprosy patients $(\mathrm{N}=$ $2,726)$ or $9.7 \%$, Sinop had the highest number of $C L$ cases $(\mathrm{N}=$ 1,262 ) or $5.1 \%$ (Figure $3 \mathrm{~A}$ and $3 \mathrm{~B}$ ).

Smoothed leprosy detection coefficients ranged from 19.5 to 456.6 cases/100,000 inhabitants, with a mean of 100.2 cases/100,000 inhabitants (SD: 69.1) heterogeneously distributed across the state territory. The highest rates were found to be concentrated in the North and Northeast (Figure 3C). For CL, the coefficients demonstrated a greater amplitude, with minimum of 2.3 and a maximum of 759.6 cases/100,000 inhabitants showing a mean of 139.9 cases/100,000 inhabitants (SD: 126.3). The highest CL detection coefficients were predominantly observed among the municipalities of the northern, north-eastern and south-eastern mesoregions (Figure 3D).
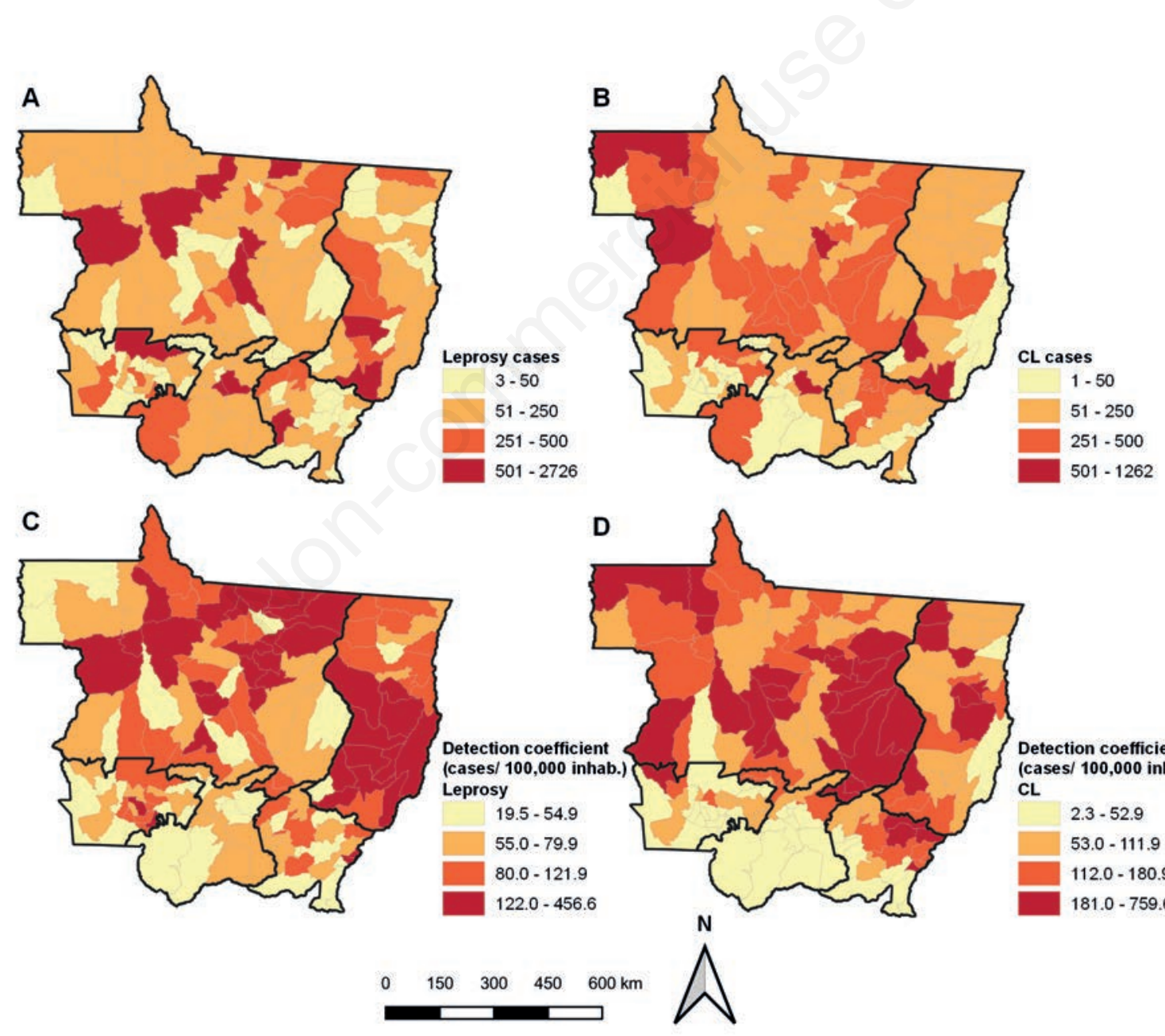

Figure 3. Cumulative number of cases and detection coefficient of leprosy and Cutaneous Leishmaniasis (CL) in the state of Mato Grosso, Brazil 2008-2017. (A) and (B) show the absolute number of cases per municipality; (C) and (D) the detection coefficient smoothed by the global empirical Bayesian estimator (cases/100,000 inhabitants) for leprosy and CL, respectively. The black lines correspond to the division of the state into mesoregions and the gray lines correspond to the borders of the municipalities. 
Kulldorff's spatial scan statistic demonstrated the existence of three high-risk spatial clusters for leprosy and two for CL. For leprosy, the clusters included $50.4 \%$ (71/141) of the municipalities and $35.6 \%(1,122,707 / 3,150,671)$ of the population of the study area. In these areas, the relative risk (RR) for disease occurrence varied from 1.5 to 5.6 times higher than the risk outside them. For CL, $66.0 \%$ $(93 / 141)$ of the municipalities, with $43.4 \%(1,368,557 / 3,150,671)$ of the state population, represented high-risk areas, with RR for disease occurrence ranging from 1.7 to 4.0 compared to other areas. Of note, an important overlap of the high-risk clusters for leprosy $(\mathrm{RR}=2.0$; $\mathrm{P}<0.001)$ and $\mathrm{CL}(\mathrm{RR}=4.0 ; \mathrm{P}<0.001)$ was identified in the northern and north-eastern mesoregions. This overlap included $45.4 \%(64 / 141)$ of the municipalities and $32.1 \%(1,012,032 / 3,150,671)$ of the total population of the state of Mato Grosso (Figure 4A and 4B).

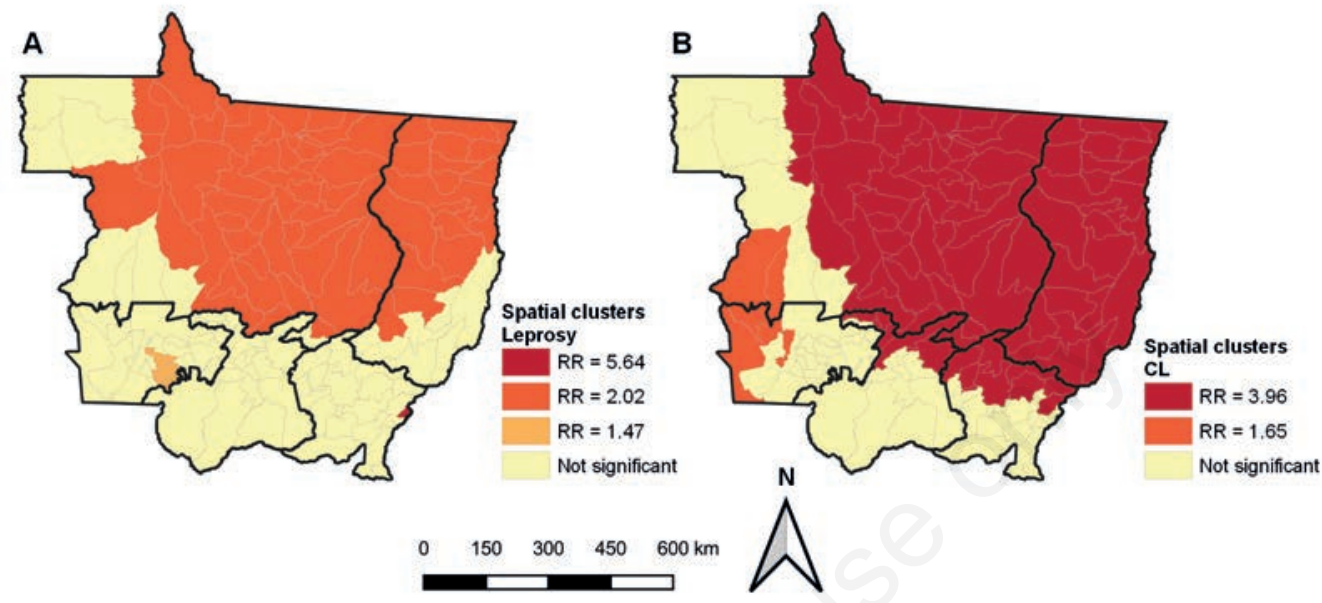

Figure 4. Leprosy and Cutaneous Leishmaniasis (CL) high-risk clusters in the state of Mato Grosso, Brazil 2008-2017 detected by the Kulldorff's spatial scan statistics. (A) Leprosy and (B) CL. The black lines correspond the division of the state into mesoregions and the gray lines correspond the borders of the municipalities.
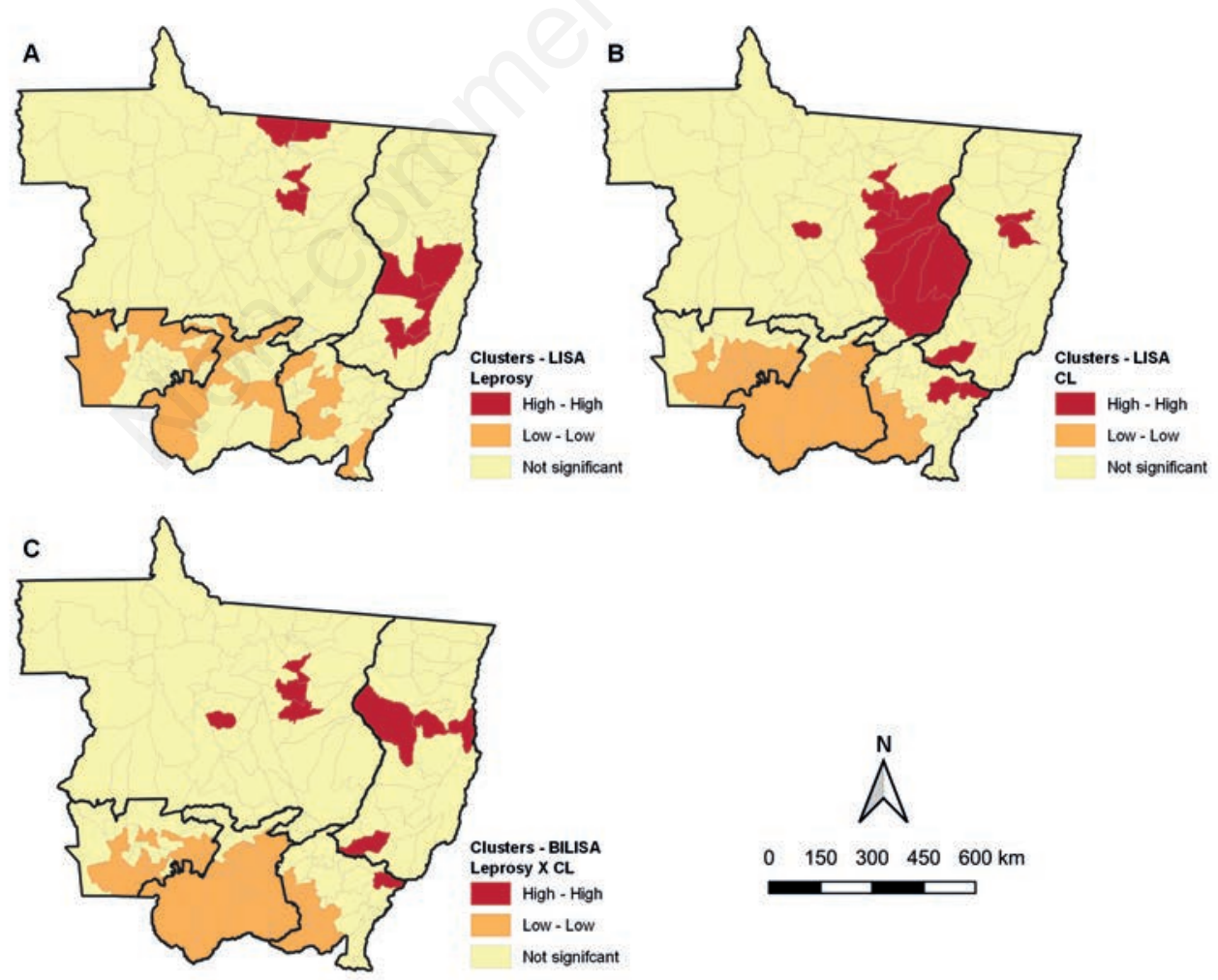

$0 \quad 150300 \quad 450600 \mathrm{~km}$

Figure 5. Local Moran's I analysis for the smoothed detection coefficients of leprosy and Cutaneous Leishmaniasis (CL) in the state of Mato Grosso, Brazil 2008-2017. (A) and (B) show the Local Indicator of Spatial Association (LISA) map for leprosy and CL, respectively; (C) shows the bivariate LISA (BiLISA) map for leprosy and CL. 
Global Moran's I for the smoothed detection coefficients revealed a significant and positive overall spatial autocorrelation for leprosy (0.228; $\mathrm{P}=0.001)$ and $\mathrm{CL}(0.311 ; \mathrm{P}=0.001)$. Figures $5 \mathrm{~A}$ and $5 \mathrm{~B}$ show that 8 and 14 municipalities were classified as HighHigh for leprosy and CL, respectively. Of note, most of them are located in the North and Northeast of the state. Low-Low municipalities were found to be exclusively located in the Southwest, Central-South, and Southeast.

The spatial correlation between leprosy and CL showed a positive and significant bivariate Global Moran's I (0.164; $\mathrm{P}=0.001)$. The BiLISA statistics revealed that leprosy detection coefficients were positively influenced by $\mathrm{CL}$ coefficients in neighbouring areas in nine municipalities (High-High). Of these, eight were distributed across the northern and north-eastern mesoregions, as clusters or individually. On the other hand, a single cluster composed of 26 municipalities with low coefficients (Low-Low) was detected in the Southwest, Central-South, and Southeast (Figure 5C).

Table 1 summarizes the sociodemographic characteristics of the leprosy and CL patients. Both diseases were seen to disproportionately affecting males of brown-skinned ethnicity, aged 31-60 years, with a low educational status and residing in urban/periurban areas. However, when compared to each other, there were important differences between the two cohorts. For CL, the proportion of male patients was much higher $(80.7 \%)$ than for leprosy
(54.6\%). For leprosy, there was a stronger predominance of individuals aged 31-60 y (59.7\%) while for CL patients this age group only represented $48.4 \%$ of the total patient cohort. With regard to education, the leprosy patients had a lower level $(41.3 \%$ with up to four years of schooling) than the CL patients (31.7\%), and compared to the CL patients (53.6\%), they were far more concentrated in urban/peri-urban areas $(81.2 \%)$.

\section{Discussion}

To the best of our knowledge, this is the first study jointly evaluating the distribution of two of the most important NTDs characterized by skin lesions - leprosy and CL - in the Brazilian state of Mato Grosso. At the municipality level, we observed an important concentration in certain regions and heterogeneity in the spatial distribution for both leprosy and CL cases. We also noted a remarkable overlap of the most endemic areas.

Mato Grosso is a historic leprosy focus (Magalhães et al., 2011). The sustained detection of leprosy patients at hyperendemic levels (>40/100,000 inhabitants) (MoH, 2020) in most municipalities of the state may in part be associated with operational improvements in the health services including better coverage and decentralization. These reforms are the result of rolling out primary care services across Mato Grosso thanks to the Family Health

Table 1. Stratification of reported cases of leprosy and cutaneous leishmaniasis (CL) according to socio-demographic characteristics in the state of Mato Grosso, Brazil 2008-2017.

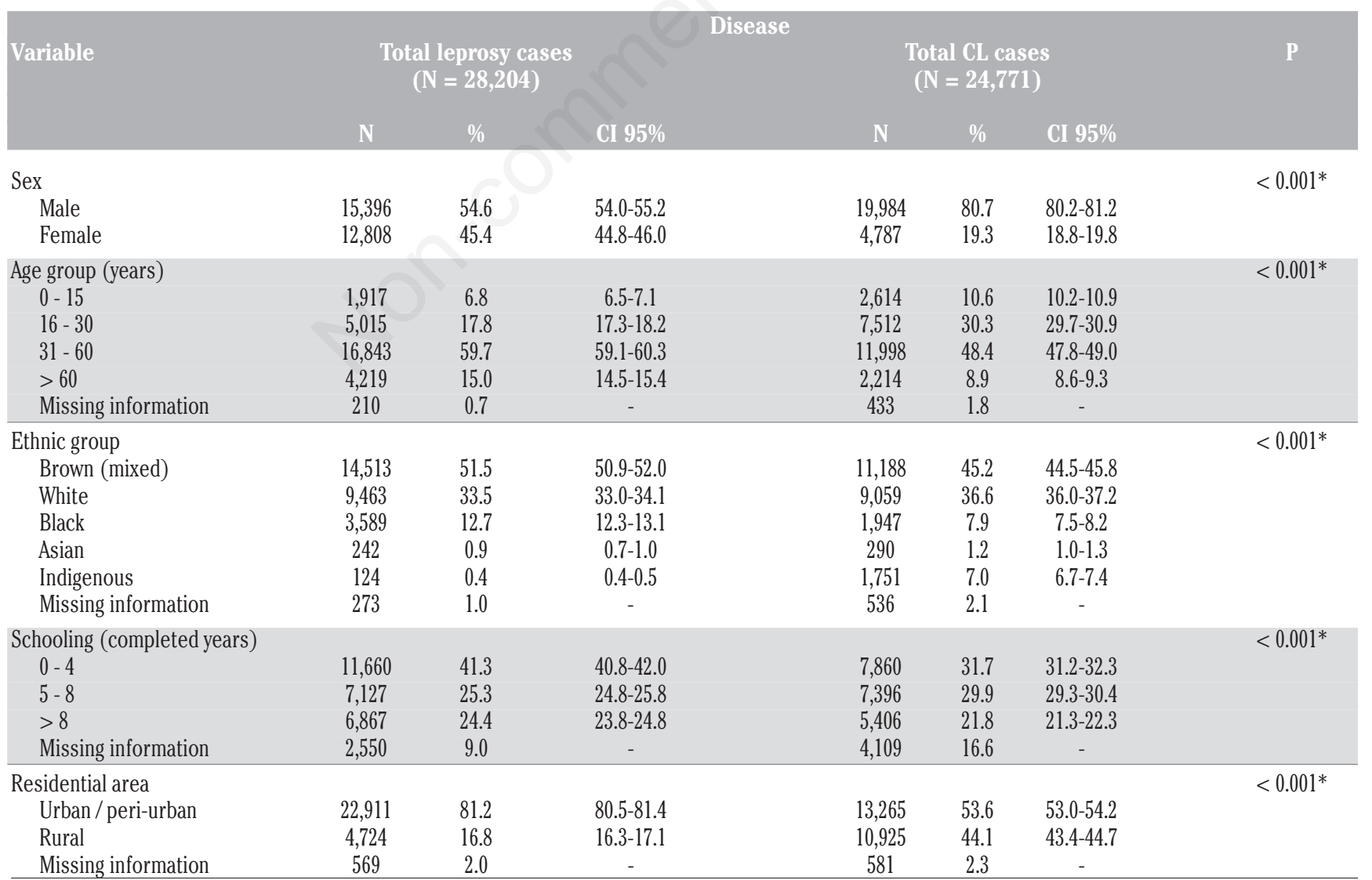

Source: Brazilian Notifiable Diseases Information System (Sistema de Informação de Agravos de Notificação, SINAN). CI 95\%: confidence interval at 95\%; \%: relative frequency; *significant at P<0.05. 
Strategy. These reforms have resulted in an increase in the number of trained health professionals and improved access to primary health care. However, prevalence data should be interpreted carefully, especially because most of the notifications still refer to passive surveillance (Magalhães et al., 2011). In addition, it should also be taken into account that the disease is often detected in areas that undergo a disorderly population growth. In fact, it was previously observed that the highest leprosy detection rates in Mato Grosso took place in areas that experienced high rates of population growth over the past decades (Magalhães et al., 2011).

Given that the economic development and associated inflow of migrants are focused in the North and Northeast, it appears plausible that these demographic shifts are linked to the observed spatial heterogeneity of leprosy. Indeed, we observed a concentration of the highest detection coefficients and high-risk clusters for the disease in the municipalities located in the northern and north-eastern mesoregions of Mato Grosso. A heterogeneous spatial distribution of leprosy was already reported for the whole country (Silva et al., 2017), with the Amazon region, where the state of Mato Grosso is partly located, being the most important endemic area nationwide (MoH, 2020).

The municipalities in the northern and north-eastern mesoregions also differ from the others with regard to environmental aspects. They represent the Amazon biome in Mato Grosso, which suffers from recent agricultural and livestock breeding expansion characterized by increasing deforestation and contact between inhabitants and remaining natural areas (Silva et al., 2010; Magalhães et al., 2011). Previous studies have already speculated about a relationship between environmental factors and the occurrence of leprosy. Rocha et al. (2017) concluded that the detection rates of the disease in Brazil present a seasonality pattern with specific variations between different geographic regions, climates, and biomes. In fact, there is evidence that changes in temperature and humidity may influence the dynamics of $M$. leprae in the environment, with environmental transmission possibly related to the intensity of exposure of the individual to contaminated soil and water (Valois et al., 2015).

All municipalities in Mato Grosso reported autochthonous CL cases with higher detection coefficients compared to the rest of the country (MoH, 2019). This concentrated occurrence is probably associated with favourable eco-epidemiological characteristics of the state. It has already been demonstrated that phlebotomine sand flies of medical importance have a wide distribution and diversity in Mato Grosso (Ribeiro et al., 2007) and naturally infected reservoirs also exist (de Freitas et al., 2012).

Although widely dispersed, CL high-risk areas were also concentrated in the North and Northeast. In these areas, as described above, forest fragments are more frequent, supporting the presence of vectors and reservoirs. In addition, an important part of the population is exposed to sand flies' bites in these areas due to the high prevalence of individuals pursuing agricultural, livestock, extractive and/or recreational activities. In fact, the demographic pattern demonstrates a concentration of infections among males, particularly in the productive age group and among rural residents, which strongly suggests a relationship between $\mathrm{CL}$ and exposure to outdoor activities, as already reported from the Brazilian states of Acre (Melchior et al., 2017) and Paraná (Melo et al., 2017). In contrast, the CL cases among children, the elderly and women suggest the presence of a peri-domestic transmission cycle, possibly due to adaptation of sand fly species to these relatively new environments and the existence of suscepti- ble reservoirs in or around habitations (Thies et al., 2016).

The positive and significant spatial correlation between the two diseases and the overlap of high-risk areas for both leprosy and $\mathrm{CL}$ are both noteworthy. Given that this co-occurrence has also been observed in other parts of Brazil, integration of control activities with regard to both these diseases should be considered (MoH, 2018), similar to what is proposed for vector-borne diseases (Golding et al., 2015) and implemented for leprosy, geo-helminthiasis, trachoma and schistosomiasis among schoolchildren $\mathrm{MoH}$, 2012). For the NTDs that predominantly affect the skin, the integration of control programs is recommended, especially because it increases cost-effectiveness and expands the geographical coverage, both with favourable impact on public health (Mitjà et al., 2017). In addition, the integrated control of leprosy and CL facilitates targeted training of health professionals for the differential diagnosis of these two diseases, which is essential for a better prognosis (Moschella and Garcia-Albea, 2016; Mitjà et al., 2017). The occurrence of leprosy may also be influenced by the occurrence of CL, specifically in the areas highlighted by the BiLISA statistics, as has already been proposed for other infectious diseases in Brazil (Phillips et al., 2017) and abroad (Aturinde et al., 2019). These two diseases share certain clinical, immunological and epidemiological aspects (Martínez et al., 2018) as reported in relation to some cases of co-infection in Brazil (Costa et al., 2009; Mercadante et al., 2018). This emphasizes the need for further detailed investigations on the extent of co-endemicity and the frequency and outcomes of leprosy and CL co-infections.

The present study has some limitations. First, we used secondary data which is generally susceptible to missing information and underreporting. However, leprosy and CL are both notifiable diseases in Brazil, and reporting is mandatory for subsequent treatment (Phillips et al., 2017). Second, due to the database structure it is not possible to determine whether diagnoses concern the same individual, nor can any causal relationship between them be identified.

Despite these limitations, the study successfully identified spatial patterns of leprosy and CL distribution in the state of Mato Grosso, with important overlaps in the North and Northeast. The results may be used to guiding surveillance and control interventions by public health authorities in the area. The identification of overlapping risk areas for leprosy and CL in the southern Amazon may further support the development of integrated public health policies to more effectively control these NTDs. In addition, it encourages new investigations addressing the co-infection between leprosy and CL on population and individual levels in Brazil and worldwide.

\section{Conclusions}

Leprosy and CL occur at hyperendemic levels and have heterogeneous spatial distribution in the Brazilian state of Mato Grosso, with extensive overlaps between the most endemic areas.

\section{References}

Alvar J, Velez ID, Bern C, Herrero M, Desjeux P, et al., 2012. Leishmaniasis worldwide and global estimates of its incidence. PLoS One 7:e35671.

Assunção RM, Barreto SM, Guerra HL, Sakurai E, 1998. [Mapas 
de taxas epidemiológicas: uma abordagem Bayesiana.] Cad Saúde Pública 14:713-23. [Article in Portuguese].

Aturinde A, Farnaghi M, Pilesjo P, Mansourian A, 2019. Spatial analysis of HIV-TB co-clustering in Uganda. BMC Infect Dis 19:612.

Carvalho MS, Câmara G, Cruz OG, Correa V, 2004. [Análise de dados de área.] In: Druck S, Carvalho MS, Câmara G, Monteiro AMV (ed). [Análise Espacial de Dados Geográficos.] Brasília: Embrapa. [Article and Book in Portuguese].

Costa JML, Saldanha ACR, Melo LS, Silva AR, Ferreira LA, et al., 2009. Cutaneos leishmaniasis (CL) associated with leprosy: a new and emerging clinicoepidemiological entity observed in the northeast of Brazil. Gaz Med Bahia 95-102.

DATASUS, 2020. [Department of Informatics of the Unified Health System.] Available from: http://tabnet.datasus.gov.br Accessed: March 30, 2020. [Website in Portuguese].

de Freitas TP, D'Andrea PS, de Paula DA, Nakazato L, Dutra V, et al., 2012. Natural infection of Leishmania (Viannia) braziliensis in Mus musculus captured in Mato Grosso, Brazil. Vector Borne Zoonotic Dis 12:81-3.

Engelman D, Fuller LC, Solomon AW, McCarthy JS, Hay RJ, et al., 2016. Opportunities for integrated control of neglected tropical diseases that affect the skin. Trends Parasitol 32:84354.

Golding N, Wilson AL, Moyes CL, Cano J, Pigott DM, et al., 2015. Integrating vector control across diseases. BMC Med 13:249.

IBGE, 2019. [Estado de Mato Grosso.] Available from: https://cidades.ibge.gov.br/brasil/mt Accessed: September 23, 2019. [Website in Portuguese].

Kulldorff M, Nagarwalla N, 1995. Spatial disease clusters: detection and inference. Stat Med 14:799-810.

Magalhães MCC, Santos ES, Queiroz ML, Lima ML, Borges RCM, et al., 2011. [Migração e hanseníase em Mato Grosso.] Rev Bras Epidemiol 14:386-97. [Article in Portuguese].

Martínez DY, Verdonck K, Kaye PM, Adaui V, Polman K, et al., 2018. Tegumentary leishmaniasis and coinfections other than HIV. PLoS Negl Trop Dis 12:e0006125.

Melchior LAK, Brilhante AF, Chiaravalloti-Neto F, 2017. Spatial and temporal distribution of American cutaneous leishmaniasis in Acre state, Brazil. Infect Dis Poverty 6:99.

Melo HA, Rossoni DF, Teodoro U, 2017. Spatial distribution of cutaneous leishmaniasis in the state of Paraná, Brazil. PLoS One 12:e185401.

Mercadante LM, Santos MASD, Pegas ES, Kadunk BV, 2018. Leprosy and American cutaneous leishmaniasis coinfection. An Bra Dermatol 93:123-5.

Ministry of Health $(\mathrm{MoH}), 2012$. [Secretaria de Vigilância em Saúde. Plano integrado de ações estratégicas de eliminação da hanseníase, filariose, esquistossomose e oncocercose como problema de saúde pública, tracoma como causa de cegueira e controle das geohelmintíases: plano de ação 2011-2015.] Available from: http://bvsms.saude.gov.br/bvs/publicacoes/plano_integrado_a coes_estrategicas_2011_2015.pdf Accessed: $\bar{N}^{-}$ovember ${ }^{-} 7$, 2019. [Website in Portuguese].

Ministry of Health $(\mathrm{MoH}), 2016$. [Secretaria de Vigilância em Saúde. Departamento de Vigilância das Doenças Transmissíveis. Diretrizes para vigilância, atenção e eliminação da hanseníase como problema de saúde pública.] Available http://portalarquivos2.saude.gov.br/images/pdf/2016/fevereiro /04/diretrizes-eliminacao-hanseniase-4fev16-web.pdf Accessed: January 30, 2020. [Website in Portuguese].

Ministry of Health $(\mathrm{MoH}), 2017$. Secretaria de Vigilância em Saúde. Manual de Vigilância da Leishmaniose Tegumentar. Available from: http://bvsms.saude.gov.br/bvs/publicacoes/ manual_vigilancia_leishmaniose_tegumentar_americana_2edi cao.pdf Accessed: September 9, 2019.

Ministry of Health $(\mathrm{MoH}), 2018$. [Secretaria de Vigilância em Saúde. Departamento de Vigilância de Doenças e Agravos não Transmissíveis e Promoção da Saúde. Saúde Brasil 2017: uma análise da situação de saúde e os desafios para o alcance dos objetivos de desenvolvimento sustentável. Doenças negligenciadas no Brasil: vulnerabilidade e desafios.] Available from: http://bvsms.saude.gov.br/bvs/publicacoes/saude_brasil_2017. pdf Accessed: November 7, 2019. [Website in Portuguese].

Ministry of Health (MoH), 2019. [Coeficiente de detecção de casos de leishmaniose tegumentar por 100.000 habitantes. Brasil Grandes regiões e Unidades Federadas. 1990 a 2018.] Available from: https:/www.saude.gov.br/images/pdf/2019/ outubro/14/LT-Coef-Deteccao.pdf Accessed: March 7, 2020. [Website in Portuguese].

Ministry of Health $(\mathrm{MoH}), 2020$. [Secretaria de Vigilânica em Saúde. Boletim Epidemiológico de Hanseníase.] Available from: https://www.saude.gov.br/images/pdf/2020/janeiro/31/ Boletim-hanseniase-2020-web.pdf Accessed: March 20, 2020. [Website in Portuguese].

Mitjà O, Marks M, Bertran L, Kollie K, Argaw D, et al., 2017. Integrated control and management of neglected tropical skin diseases. PLoS Negl Trop Dis 11:e0005136.

Moschella SL, Garcia-Albea V, 2016. Differential diagnosis of leprosy. In: Scollard DM, Gillis TP (ed). International Textbook of Leprosy. Available from: https://m3u9w4p9.stackpathedn. com/sites/default/files/ITL_2_3\%20FINAL.pdf Accessed: February 12, 2020.

Phillips DA, Ferreira JA, Ansah D, Teixeira HSA, Kitron U, et al., 2017. A tale of two neglected tropical infections: using GIS to assess the spatial and temporal overlap of schistosomiasis and leprosy in a region of Minas Gerais, Brazil. Mem Inst Oswaldo Cruz 112:275-80.

QGIS, 2018. Development Team. Quantum GIS geographic information system. Open source geospatial foundation project, v. 3.4 Madeira. Available from: http://qgis.org Accessed: April $10,2019$.

Ribeiro AL, Missawa NA, Zeilhofer P, 2007. Distribution of phlebotomine sandflies (Diptera: Psychodidae) of medical importance in Mato Grosso State, Brazil. Rev Inst Med Trop Sao Paulo 49:317-21.

Rocha ACAA, Junger WL, Cruz WJA, Ignotti E, 2017. The impact of seasonal climate on new case detection rate of leprosy in Brazil (2008-2012). Lepr Rev 88:533-42.

Rodrigues LC, Lockwood D, 2011. Leprosy now: epidemiology, progress, challenges, and research gaps. Lancet Infect Dis 11:464-70.

Silva DRX, Ignotti E, Souza-Santos R, Hacon SS, 2010. [Hanseníase, condições sociais e desmatamento na Amazônia brasileira.] Rev Panam de Salud P 27:268-75. [Article in Portuguese]

Silva CLM, Fonseca SC, Kawa H, Palmer DOQ, 2017. Spatial distribution of leprosy in Brazil: a literature review. Rev Soc Bras Med Trop 50:439-49. 
Standley C, Boyce MR, Klineberg A, Essix G, Katz R, 2018. Organization of oversight for integrated control of neglected tropical diseases within Ministries of Health. PLoS Negl Trop Dis 12:e0006929.

Thies SF, Bronzoni RVM, Espinosa MM, Souza CO, Ribeiro ALM, et al., 2016. Frequency and diversity of phlebotomine sand flies (Diptera: Psychodidae) in Sinop, State of Mato Grosso, Brazil. Rev Soc Bras Med Trop 49:544-52.

Valois EMS, Campos FMC, Ignotti E, 2015. Prevalence of
Mycobacterium leprae in the environment: a review. Afr J Microbiol Res 9:2103-10.

WHO, 2017. Integrating neglected tropical diseases into global gealth and development. World Health Organization, Geneva, Switzerland. Available from: https://www.who.int/neglected_ diseases/resources/9789241565448/en/

WHO, 2019. Weekly epidemiological record. Global leprosy update, 2018: moving towards a leprosy-free world. Wkly Epidemiol Rec 94:389-412. 